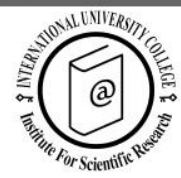

\title{
Incorporating sustainability into tourism policy: A strategic agenda for Spain
}

\author{
Yaiza López-Sánchez ${ }^{1}$ and Juan Ignacio Pulido-Fernández ${ }^{2 *}$
}

Received: 03/04/2013 Accepted: 12/06/2013

\footnotetext{
${ }^{1}$ Laboratorio de Análisis e Innovación Turística (LAInnTUR), Departament of Economics, University of Jaén, Campus Las Lagunillas s/n, 23071 Jaén, Spain; phone: +34 953212070; e-mail: ymlopez@ujaen.es

${ }^{2}$ Laboratorio de Análisis e Innovación Turística (LAInnTUR), Departament of Economics, University of Jaén, Campus Las Lagunillas s/n, 23071 Jaén, Spain; phone: +34 953212070; e-mail: jipulido@ujaen.es

* Corresponding author
}

\begin{abstract}
Recent literature recognises that sustainability, as well as a shifting approach to responsibility in tourism production and consumption, may be a differentiator in the positioning of destinations in tourism markets, especially in the most demanding ones. Likewise, it is acknowledged that it will be difficult to make progress in tourism sustainability without a direct, clear and resolute involvement of policymakers in destinations management. Therefore, the incorporation of the paradigm of sustainability in tourism policy is a key issue.

This paper proposes a methodology for incorporating sustainability into tourism policy. Using qualitative analysis techniques (Delphi and focus group), an assessment is carried out, leading to the subsequent design of a strategic agenda for incorporating sustainability into Spanish tourism policy. Spain has been chosen as one of the world's top tourism destinations, which is also currently undergoing a restructuring process of its tourism model, too dependent on coastal tourism, which is considered exhausted, obsolete and lacking in competitiveness.
\end{abstract}

(c) 2014 International University College. All rights reserved.

Keywords: sustainability, tourism policy, policymakers, value chain, Spain.

Citation: López-Sánchez, Y., J.I. Pulido-Fernández (2014) Incorporating sustainability into tourism policy: A strategic agenda for Spain. European Journal of Tourism Research 7, pp. 57-78.

\section{Introduction}

For many national economies, including the members of the G-20, tourism is seen as a key driver of post-crisis recovery and, in fact, is frequently integrated into general economic response policies (Goldin, 2010). However, nowadays, the most conventional tourism plans are dominated by the growing needs of the tourism industry and are generally designed with the aim of increasing visitor numbers, volume of business and job creation. In the same way, another type of tourism planning is often formulated only in terms of land use and physical planning, so it may have little regard for community, environment, culture or enterprise (Lane, 2012).

Most literature recognises that, while it is true that the concept of sustainability is generally accepted and incorporated a priori in planning processes, however, a real transformation 
towards a new tourism model focusing on sustainability as its core value has not occurred so far. And this is due, in large part, to policymakers and tourism destinations managers who do not really know what this paradigm implies, misinterpret it, or attach less importance to it than to other aspects of the tourism business.

It is necessary, therefore, to develop effective tools that enable the translation of the ideals and principles of sustainability into actions. If this does not occur, sustainable tourism is at risk of remaining theoretical, and becoming irrelevant as a viable policy option. Therefore, policymakers and tourism destination managers must incorporate sustainability as a key variable in planning and management decision-making processes.

In this paper, an analysis and intervention proposal has been put forward to, through the use of three methodological tools (value chain, Delphi and focus group), allow policymakers and tourism destination managers to make the best decisions, focusing their resources and efforts on those factors that contribute to a greater extent to the generation of the value perceived by the customer, in terms of sustainability, and, consequently, improving the efficiency of their intervention. The proposed methodology is applied in Spain, a world renowned tourism destination, which receives almost 58 million international arrivals and grosses more than one hundred billion euros a year from tourism, generating over $11 \%$ of the national GDP in 2012 and two million new jobs.

The main strength of this paper is its clear commitment to put theory into practice. Therefore the results obtained allow to distinguish between three types of contributions: theoretical developments, empirical contributions and practical implications.

\section{Literature review}

The sustainability paradigm has become in recent years a key element of the debate on tourism destination management. Sustainable tourism is presented as a way to carry out the tourism activity based on the ideology of sustainability. In connection with this idea, some authors (Hamel, 2005a, b; Folch, 2008 2009, Hidalgo-Capitán, 2012) use the neologism "sustainabilism" to refer to a culture, a philosophy or a philosophical paradigm inspired by a conception of sustainability derived from the concept of sustainable development (Brundtland, 1987) and its interpretations grounded in the theory of its three pillars (economic, social and environmental) (Chambers, 1986, 1987; Munasingue, 1993; among others). The concept of "sustainabilism" can be defined as the ideology of sustainability, and it would be "that set of ideas and values, based on sustainability, about the regulation of the world economic system, (and of the national economic systems which are part of it), which aims to guide the behaviours (decisions and habits) of the system regulator agents" (Hidalgo-Capitán, 2012: 8). However, the problem in achieving sustainability does not lie in the acceptance of its definition, academically overcome and assumed, but in its actual application (Wheeler, 1993; Dodds and Butler, 2009, Waligo et al., 2012).

Sustainability is a key factor in ensuring the competitiveness of any destination. However, "it is not the solution spontaneously chosen by the market" (Riera et al., 2009: 390). Consequently, the government -which in this research paper refers to the State/central government, due to inter-regional, interdepartmental and intersectoral coordination capacity- must take on the challenge of sustainability, leading a coordinated public action that provides the "environmental conditions" needed for the consolidation of a new tourism model in which sustainable tourism production and consumption patterns prevail, creating more value, satisfaction and well-being, but with a gradual reduction in the use of material and energy. As Riera et al. (2009: 377) point out, "if economic agents behave irrationally and try to seek the maximum individual benefit, they can come across socially inefficient situations, that is, which do not generate the maximum welfare for society", hence the need for the government to take the lead in formulating tourism policy. This, as these same authors remind us, does not involve its management, but the generation of a favourable environment and the necessary 
incentives for all stakeholders to negotiate, discuss and eventually, cooperate to achieve the set objectives. In order to succeed in cooperating towards a sustainable tourism development, stakeholders must be convinced that the result will be positive and represents a constructive response to their priorities (Prigram, 1990). Therefore, for the sustainable management of a destination, viable in the long term, it is important to understand the points of view of the interested parties, as they may either encourage or impede sustainability (Dodds, 2012).

The challenge of sustainability requires government and industry to face the complexities associated with the development of sustainable tourism (Harris et al., 2002), each one of them with its own capacity of action and responsibility. According to Voinov (2008), sustainability is now a political issue rather than a scientific concept. In fact, it should be "a policy that makes it possible to engage in its characterization all the sectors, levels and guiding principles that take part in it" (Enríquez et al., 2012: 425). Therefore, a coordinated public action which provides a comprehensive and stable framework is required, bringing together all sectoral policies affected and allowing the development of guidelines and lines of interdepartmental and intersectoral action, in favour of new tourism management patterns that deal with the implications of sustainability in depth.

The transformation towards a sustainable tourism model begins with the implementation of a comprehensive tourism management policy that ensures the sustainable development of the destination. In this sense, the Government, through its different institutions, is responsible for planning and regulating economic activities. Thus, the administration, through tourism policy, participates in tourism activity as being an integral part of the economic activity of the country. It is evident that the different tools emanating from the administration are essential for the management, control and development of tourism activity and, on the other hand, all actions of tourism in pursuit of sustainability must be consistent with the general regulations (Cebrián, 2008).
Given that tourism is one of the most globalised economic activities (Pulido \& López, 2011), managing and developing tourism from a sustainable perspective will favour a transition to sustainable economic models. There is an urgent need to develop policies and measures not only in theory and on paper, but also in practice (Liu, 2003). In that respect, some studies exist on the implementation of tourism policies (Jenkins, 1980; Younis, 1990; Choy, 1991; Dye, 1992; Johnson \& Thomas, 1992; Hall, 2000; Hall \& Jenkins, 1995, among others) which are sceptical about the role of government, its intentions and the actual impact of government policies. More specifically, other studies about the incorporation of sustainability into tourism policy (WTO, 1998; UNEP \& ICLEI, 2003; Dodds \& Butler, 2009; Sharpley, 2009; Goldin, 2010; Yasarata et al., 2010; Yüksel et al. 2012, among others) show that the initial agreements and declarations, despite being widely accepted by many governments and international organisations, are not as effective from the point of view of its implementation.

In fact, the incorporation of sustainability into public policy is often hindered by a wide range of obstacles. A research study by Dodds \& Butler (2009) identifies numerous barriers to the success of the actual incorporation of sustainability into tourism policies. It is worth highlighting the following: economic priority short term focus, concentration on numbers vs. yield-, stakeholder support -lack of participation, loss of long term vision and commitment-, power struggle between ministries, lack of communication between authorities, lack of holistic focus as tourism as part of core economy, more money towards marketing than sustainability, opposing political parties - lack of will, lack of clear structure for roles and responsibilities, etc.

This shows that, without the development of effective tools to translate the ideals and principles of sustainability into practice, sustainable tourism runs the risk of remaining theoretical, becoming irrelevant as a viable policy option. Although sustainability is acknowledged as a key factor of tourism destination competitiveness (Buhalis, 2000; Hassan, 2000; Ritchie \& Crouch, 2003), the 
success of the actual incorporation of sustainability into the value chain of the destinations depends on its acceptance and development by policymakers and tourism destination managers. All this through tourism policies aware of the real challenges they face.

Incorporating sustainability into tourism policies should begin from a real awareness of the overall and systemic situation of the tourism destination, to thereby assist policymakers to address the complexities of sustainable tourism and make more informed decisions. This will allow incorporating the principles of sustainability throughout the value chain of the destination.

\section{Case study}

In this research study, the implementation of the proposed methodology was carried out in a representative international tourism destination: Spain, which receives almost 58 million international arrivals and grosses more than one hundred billion euros a year from tourism, generating more than $11 \%$ of GDP in 2012 and two million new jobs.

Tourism activity has been, for decades, the main driving force of growth in the Spanish economy, positioning itself as one of the main drivers of economic development in this country by contributing significantly to the balance of payments, GDP and employment. From its beginnings as a mass phenomenon in the $50 \mathrm{~s}$, tourism is recognised as an economic activity which generates multiple economic benefits and is, undoubtedly, appropriate for the development of the territory. However, this not only generates positive economic effects in the destination, but it is also the immediate cause of many impacts, both positive and negative, in several contexts: economic, social, environmental, cultural, etc.

The lack of an appropriate sustainable strategic tourism planning has generated numerous impacts on the territory, which reveals a traditional tourism model, exhausted and unsustainable. It is, therefore, essential that tourism activity introduces the principles of sustainability throughout the value chain of the destination (Pulido, 2011). Spanish destinations have the need to manage the change towards a sustainable tourism model 60
(Vera and Baños, 2010), which requires the development of policies and measures which do not remain in theory and on paper, but encourage a real change instead.

Although literature on tourism policy exists in Spain, the issue of sustainability in the Spanish tourism policy has been discussed only partially and tangentially up to now (Pulido, 2004; Velasco, 2010). Therefore, it is proven the novelty of the subject under study and the opportunity to determine the level of incorporation of sustainability within the tourism policy of Spain, the world's second destination ranked by tourism income.

In order to achieve the transition of the current Spanish tourism model - exhausted and obsolete, according to most of the literature consulted (Perelli, 2011, Pulido, 2011; Vera and Baths, 2010, among others) -, towards a more sustainable one, general guidelines aimed at achieving a general economic progress that is aware of the limits to the exploitation of resources are needed. A simplistic and sectoral approach to the tourism sector must be avoided, while their integrated planning and management must be sought. Knowing the clear signs of exhaustion of the Spanish tourism model, it is necessary to "undertake structural transformations, in both comprehensive planning and administrative coordination and in the tourism industry itself to revaluate the value chain in an efficient and competitive way" (Jiménez, 2007: 74). For this, it is crucial to identify the main errors and problems of the current tourism policy as regards sustainability, which will enable the identification of the main issues that should be included in the Spanish tourism policy to improve the sustainability of tourism, concluding with the design of a strategic agenda to guide the formulation of a tourism policy in Spain in terms of sustainability.

\section{Methodological framework}

The methodology developed for this research begins with an in-depth literature review, which allowed for a thorough understanding of the subject to be studied and the selection of the future experts participating in the research study. The survey was designed as well. Thus, in order to structure the analysis performed in a 
logical sequence, it was decided to use the concept of value chain of the tourism destination as a methodological tool, since it makes possible the identification of each of the links through which value is added to the experience enjoyed by the tourist at the destination. This tool has enabled design of a survey which gathers the main problems currently existing in each of the links in the value chain.

Afterwards, two methodological tools - Delphi and focus group - have been used in order to elicit the views of the experts regarding the current situation and the future possibilities of incorporating sustainability into Spanish tourism policy.

First, the Delphi analysis was initiated, with the aim of obtaining an assessment of the major errors and problems of the current Spanish tourism policy on sustainability. For this research study, a group of 30 experts was selected nationwide, with the following characteristics:

Professors who are familiar with research and tourism planning, and specialists in different areas of knowledge related to sustainability (economics, geography, sociology, political science, etc.) (20 of the 30 experts invited).

$\checkmark \quad$ Skilled government technicians (6 of 30 experts invited).

$\checkmark$ Members of institutions and/or business organisations linked to tourism (1 of the 30 experts invited).

$\checkmark \quad$ Professionals consultants with
experience in tourism planning and
management ( 3 of the 30 experts invited).

In parallel with Delphi, the focus group was initiated (Figure 1). It was subjected to a threestage process, between July and September 2012, with a total of 6 participants (2 professors, two government technicians, 1 representative of tourism business associations, of national prominence, and 1 tourism consultant). In the first stage, once obtained the approval of the experts taking part in the process, they were sent a document with information about the aim of this research and the role that the focus group should carry out, as well as a guide with its rules of operation, the work plan and a preliminary assessment of the current situation of tourism development in Spain from the point of view of sustainability, specifically developed for this research on the basis of the literature reviewed and the results obtained in the first round of the Delphi study. The goal, in this case, was to initiate a first round of discussion about what might be the main elements that make up the new Spanish tourism policy, incorporating the vision of sustainability.

In a second stage, with the final report of the Delphi analysis, the members of the discussion group were called to several business meetings in which specific issues relating to future planning, management and marketing strategies of tourism in Spain, but from the perspective of the transformation of this model in terms of sustainability. The discussion of the first meeting began with a general question to all participants about the main aspects that should be included in a possible strategic agenda to incorporate sustainability into the planning, management and marketing of Spanish tourism. After identifying these aspects, experts were asked to rate the different aspects identified on a Likert scale from (7) extremely important to (1) extremely unimportant.

Having tabulated the information obtained in this first meeting, experts were called to a second meeting, in which they were provided with a simple statistical summary of the answers given by the group in the first round, and of their own individual responses. Then, they were asked express themselves on the same issues, reconsidering their positions if they believed it necessary, in light of the group's responses. Before voting, there was an open and participatory discussion, in which all the experts pronounced on the results obtained in the first round. 
Table 1. Methodological framework (tools)

\begin{tabular}{c|l}
$\begin{array}{c}\text { Methodolo } \\
\text { gy }\end{array}$ & \multicolumn{1}{c}{ Theoretical contributions } \\
\hline & $\begin{array}{l}\text { The concept of value chain was made popular by Porter (1985) as a basic instrument to describe the } \\
\text { progress of the activities within a business organization, generating value to the final customer. To } \\
\text { date, there are few published research papers about the tourism value chain, more specifically about } \\
\text { tourism destinations (Evans et al., 2003; Poon, 1993; Yilmaz y Bititci, 2006; Yunpeng et al., 2011; } \\
\text { Zhao et al., 2009, Zhang et al., 2005). After a review of the different adaptations of the concept of value } \\
\text { chain to the tourism industry (Poon, 1993; Fabricius, 2001; Evans et al., 2003; Yilmaz y Bititci, 2006; } \\
\text { Michel y Phuc, 2007; Zhao et al., 2009; Yunpeng et al., 2011; entre otros), the links of the value chain } \\
\text { of a destination have been identified. The proposed model comprises nine links, organized, at the } \\
\text { same time, in three stages that follow the logical time sequence in the process of generation of value of } \\
\text { a destination to its potential clients: }\end{array}$
\end{tabular}

\section{chain}

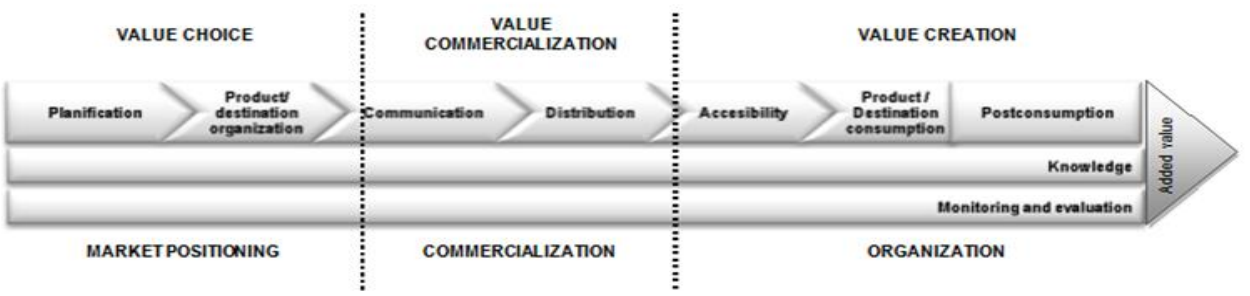

Delphi analysis is based on the principle of collective intelligence and aims to reach consensus of opinion among a group of experts on the subject under study. This is a forecasting technique for obtaining qualitative or subjective information, though relatively accurate in a setting of imperfect information, as a result of combining the knowledge and experience of experts in different fields, in a way that tends toward a consensus of opinion on future specific effects, quantifying statistically, in turn, these opinions, through measures such as: mean, median and quartiles. Its origin is based on the traditional notion that " $n$ " heads are better than one (Dalkey et al., 1972). Linstone and Turoff (1975: 3) defined it as "a method for structuring a group communication process so that the process is effective $D E L P H I$ in allowing a group of individuals as a whole to deal with a complex problem". Its purpose is, therefore, to take advantages of "group" methods and reduce the negative effects (especially psychological) of the interaction in group or face-to-face meetings. International experiences in the use of the Delphi method in tourism offer an extensive background knowledge, which demonstrates that the Delphi method is suitable for its application to tourism research. It is worth highlighting, among others, the research papers of Briedenhann and Butts (2006), Donohove (2011a and 2011b), Donohove and Needham (2009), Green et al. (1990), Kaynak and Macaulay (1984), Liu (1988), Lloyd et al. (2000), Miller (2001), Pan et al. (1995), Park and Yoon (2011), Seely et al. (1980), Spenceley (2005), Taylor (1976), Van Ginneken (2011), Weber and Ladkin (2003), Wheeller et al. (1990) o Yong et al. (1989).

The focus group technique facilitates obtaining information and opinions from different individuals (independent and renowned experts), who can even be physically distant, and enables the generation of ideas with open answers, well-structured and with an additional qualitative component. Focus group is a qualitative analysis technique that allows finding ideas and solutions aimed at addressing a specific problem (Aaker et al., 2003). Given the flexibility of the method, it can be used in a great variety of contexts and in a wide range of research paradigms, being particularly effective in capturing

Focus the complexity of a given context and analysing the way in which participants value and define key group concepts in their own words (Thomas, 2004). According Gomm (2004: 172), "the hallmark of focus groups is the explicit use of group interaction to produce data and insights that would be less accessible without the interaction found in a group". Most focus groups consist of between 6 and 12 people. In fact, as noted by Merton et al. (1990: 137), "the size of the focus group should not be so large as to be unwieldy or to preclude adequate participation by most members, nor should it be so small that it fails to provide substantially greater coverage than that of interview with one individual". Krueger (1998), meanwhile, suggests a combination of 6 to 8 members, a size which, according to this author, is ideal to ensure a genuine process of discussion.

Source: Authors' own elaboration.

Once the debate was concluded, a new vote was taken on the aspects that were being evaluated, using the same Likert scale as in the first round. It is worth noting that, with experts' permission, it was decided to double count the votes, i.e., a total of 12 votes, 6 per round. In the third and final stage, the focus group focused on validating, with a high level of agreement, the aspects agreed in the meetings of the previous stage. Thus, contents for a 
Table 2. Survey data sheet (Delphi and focus group)

\begin{tabular}{c|c|c}
\hline & Delphi & focus group \\
\hline Sample size & $\begin{array}{c}\text { First round: } 30 \text { experts } \\
\text { Second round: } 28 \text { experts }\end{array}$ & 6 experts \\
\hline Date of the empirical work & July-August 2012 & July-September 2012 \\
\hline
\end{tabular}

Source: Authors' own elaboration.

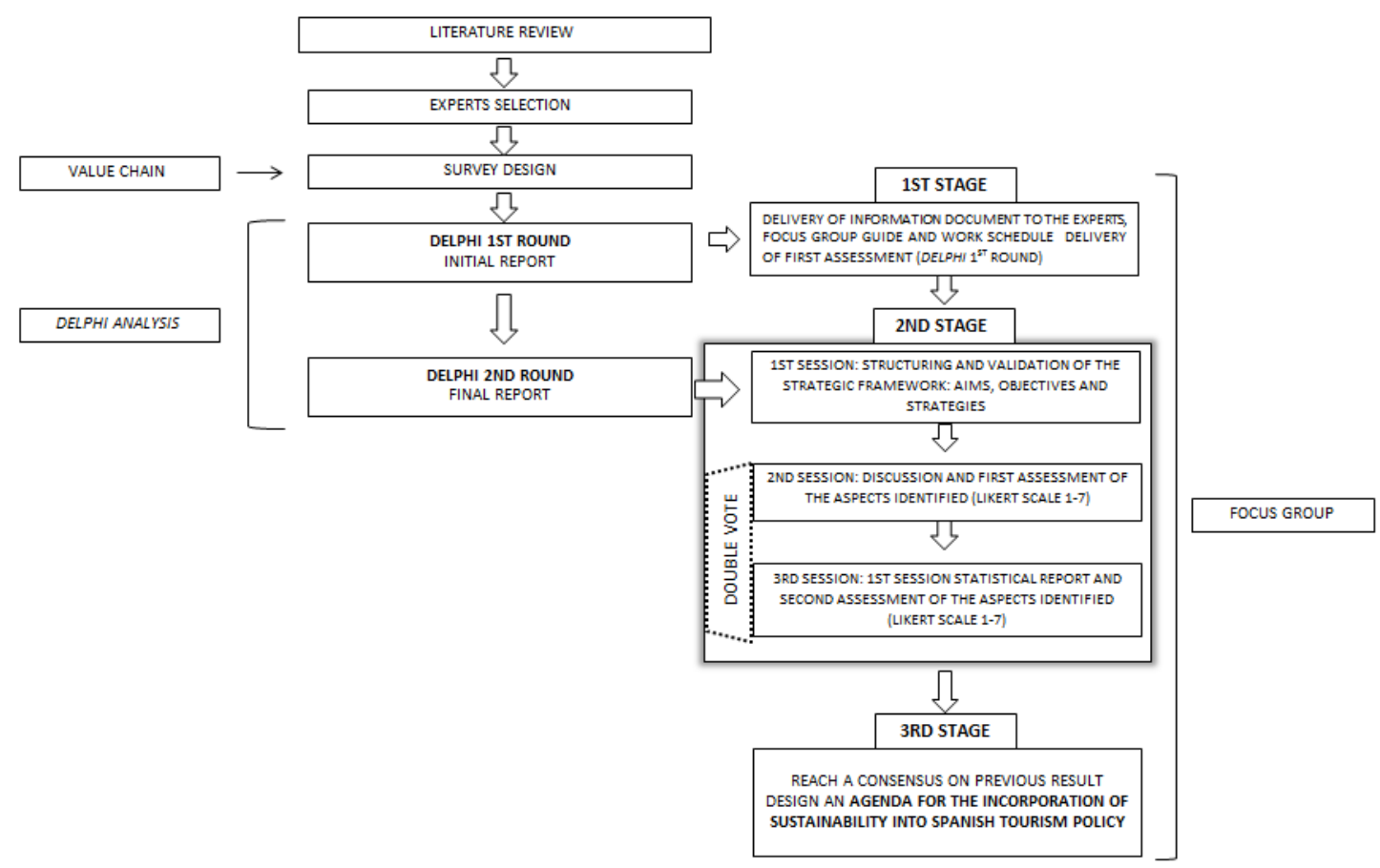

Figure 1. Methodological framework (steps)

Source: Authors' own elaboration.

future agenda for action were proposed, creating a strategic framework for the incorporation of sustainability into Spanish tourism policy.

Considering that the value of this paper lies in the application of the methodology and the analysis of the results, the main theoretical contributions of the methodology used are briefly summarised (Table 1) below.

Regarding Delphi analysis, it should be noted that, as indicated by Donohoe and Needham (2009), a drawback of this technique is the difficulty in determining when sufficient consensus has been reached, which led to the proposal of some subjective measures that are commonly usually employed to solve this problem. Following these recommendations, this paper will, firstly, consider that a broad consensus has been reached when $60 \%$ of the experts, or more, have chosen the median value; enough consensus, when between $30 \%$ and $59.99 \%$ of the experts have chosen the median value; and little consensus when at least $30 \%$ of the experts consulted had chosen the median value. Moreover, it will be considered that there is broad consensus when the interquartile range does not exceed 0.7 (which would be $10 \%$ of the 7 points in the Likert scale used); considerable consensus when the value of the interquartile range is between 0.7 and 1.5; and insufficient consensus when the value of the interquartile range exceeds 1.5 . 
Finally, Table 2 includes information on size of the sample in both studies as well as their time schedule.

In short, the proposed methodology is ideal to respond to the proposed research objective and, besides, can be applied to any destination that seeks to know its actual situation regarding the incorporation of sustainability into its tourism policy and to undertake strategic changes in its political agenda to encourage the consolidation of more sustainable tourism models.

\section{An assessment of sustainability in Spanish tourism policy}

The first stage of the research involved performing a Delphi analysis in order to seek the views of a selected group of experts on aspects relating to the situation of tourism in Spain from the point of view of sustainability, and the possibilities of a change in tourism policy in which the latter becomes central to the action of the main actors that make up the different links in the value chain. This first assessment (Table 3) allows for discussion which could be based on the main elements defining the new Spanish tourism policy, incorporating the vision of sustainability.

For each of the proposed items, the central tendency measure used has been the median (Q2), which is the central tendency most commonly used for opinions in groups. This figure occupies the central value of the distribution, that is, it contains 50 per 100 of participant responses, which means that it has as many values above it as below it, once all the elements of the population or the sample are in order. This variable is used when the arithmetic mean is strongly distorted by the existence of outliers.

Interquartile range has been used as a measure of dispersion. This measure represents "the range of the middle half of the scores" (Nick and Lee-Ross, 1998: 104). It is calculated by ordering the data from highest to lowest, showing the difference between the value placed on the left by 75 per cent of the ordered responses (third quartile, Q3) and the value placed on the left by 25 per cent of them (first quartile, Q1). This measure of dispersion is the most commonly used in most Delphi studies, given that, the shorter the distance, the greater the stability of the responses and the convergence of views. Its reduction in successive rounds of the process shows the approach to agreement or consensus among experts, which ensures the objectivity of its results and its quality.

The main aspects identified in each of the links of the value chain are summarised below.

The first link of the destination value chain is planning, which includes issues related to three main aspects: land management, planning of human resources and everything related to legal regulations and financing. It is worth highlighting that, according to experts, so far there has not been a real commitment to sustainability as a key element of the planning and management of tourism development in Spain. Moreover, they argue that the actions carried out on sustainability have a clear environmental orientation, disregarding its other dimensions, which, again, has hindered progress in this country in terms of sustainability.

On the other hand, they reflect on the negative situation caused by the erroneous link which, during the so-called real estate boom, was made between tourism and construction, due to the instrumentalisation of the former to satisfy a dynamic of real estate production with a serious impact on the sustainability of Spanish tourism destinations. This process, besides, has generated an oversupply of housing, disproportionate to the demand-generation capacity, which needs to be redefined as tourism supply.

Furthermore, experts admit that, despite the negative experiences during the last decade, no restrictions have been placed on the urban development of Spanish tourism destinations, especially along the coast. In conclusion, there is almost universal agreement on the need to change traditional ways of planning, incorporating new dynamics, approaches and tools, which make it possible to overcome political cycles and ensure continuous adaptation of the destinations to the rapid changes occurring in their environment and their own internal dynamics. 
Regarding human capital, experts believe that the image and attractiveness of the tourism sector as an employer, with respect to current and future employees, is very poor. Moreover, they argue that the "culture of sustainability" is not incorporated as a cross-curricular competence in the university training of future tourism professionals, and also that the vast majority of businesses spend scarce resources on the general education of their human capital, particularly on those issues related to sustainable management. This shows that efforts should be made for the quality of human capital to enable the development of a strong and sustainable industry, capable of competing in a global environment and facing changing situations (Lillo, 2009).

As far as tourism legislation is concerned, respondents consider that it is too dense and complex, which hinders users actions, whether they are providers (high management costs) or customers (many and complex administrative procedures). What is more, they consider that there is no legal framework regulating the relationship between tourism and urban development that encourages tourism development based on the sustainability and quality of the territory's own resources. That is, there is no legal regulation consistent with a sustainable tourism model.

Concerning the financing of the tourism sector, experts state that Government's investment and financial support to the tourism sector are insufficient, in view of its contribution to GDP and employment generation. Furthermore, they consider that the distribution of public and private funds in tourism-related investment is inefficient, since it is invested in actions of little strategic interest while others that could have a greater impact are left aside. In addition, the group declares that there are no priority and efficiency criteria for allocating funds to the actions to be developed in tourism planning.

The second link in the value chain provides an analysis of the configuration of the Spanish tourism destinations and the actions aimed at organising the products and services that make them up in a comprehensive manner. Regarding the main type of tourism in Spain, sun and sand tourism, experts strongly agree that it is essential for Spanish tourism, and that it will continue to be the main attraction, both for international markets and the internal market. In this sense, it is noteworthy that, is spite of the efforts of the administration, especially economic, to improve the competitive position of Spanish tourism in recent years, the results have been scarce, since, as experts agree, the main Spanish tourism product remains, essentially, the same as always. However, respondents consider that it is possible to generate a tourism offer different from the current one, since Spain has the necessary resources and capabilities, but lack institutional leadership and entrepreneurial vision. Similarly, with regard to the current tourism demand of the country, a high level in agreement is shown with the fact that little is done in Spain to appeal to more sophisticated tourists and/or to encourage them to demand more of the Spanish tourism offer in terms of quality, innovation and, of course, sustainability. That is, the Spanish administration must promote more selective processes to attract those tourists that it wants for its destinations, because their success or failure depends on them. In fact, according to respondents, in recent years there has been an increase in tourism phenomena related to the "trivialization" and "acculturation" of some Spanish destinations, jeopardising Spain's image as a tourism destination. Confirming the criticism of this issue voiced from the scientific field, experts show considerable agreement on the existence of the common mistake of considering sustainable tourism as a product, as it is a way of developing tourism based on the ideology of sustainability, and not a type of tourism, neither a tourism product.

Regarding the communication strategy of the destination, which affects its tourism development either by supporting its market position or by contributing to its decline, experts believe that the country does not have a wellestablished international image as a tourism destination committed to sustainability as one of its hallmarks, but it conveys an image of cheap sun and sand tourism destination, permissive of excesses (alcohol, sex, etc.), making it difficult to position in other markets or segments, more interesting from the point of view of tourism business and attraction of 
tourists who are more respectful of resources, culture and identity. As Casanueva (2010: 65) noted, "it is not just a matter of being known. The important thing is to be appreciated and, regarding this, the 'Spain brand' is weak or, even worse, it is perceived far from reality". Therefore, it is essential to overcome completely the idea behind the Spain is different (bulls, party, etc.) of the 60's, to project the professionalism, quality and uniqueness that our tourism destinations should arouse. That is to say, in order to improve their image, destinations should improve, thus ensuring that the reality matches the projected image. Moreover, another of the deficiencies identified by the experts is that a significant number of Spanish territories which are not consolidated as tourism destinations maintain an individualistic attitude in their promotion policies, which, apart from being wasteful, limits a comprehensive view of the destinations of which they are, or could be, part. Besides, the promotion of Spanish tourism offer is not coordinated with the creation of the tourism product, let alone planning actions, so these two actions (planning and promotion) seem to be independent form each other. These problems generate a certain lack of coordination and dispersion of efforts regarding promotion.

The assessment of the distribution (commercialisation) of Spanish tourism also brought some key issues to be considered. It is true that, traditionally, foreign tourists came to Spain through the intermediation of European tour-operators and their tour packages, which allow them to "develop and promote Spanish tourism, and sell our tourism product as a cheap mountain range covered with water under a scorching sun" (Pedreño and Ramón, 2009: 246). In fact, the expert panel strongly agrees that the major Spanish tourism businesses, especially hotels, have been insufficiently involved in the "Spanish control" of our tourism offer in international markets. They also confirm that neither the government nor tourism businesses have been concerned about the consolidation of a powerful Spanish tour operator that competes in international markets and "release" Spanish businesses from the abuse of control of international tour operators, although, in this sense, ICT have changed the tourism scene and will modify, even more, the future of tourism intermediaries. However, experts show a high level of agreement on the fact that, except for major Spanish tourism businesses, the rest of them have a significant technological deficiency that makes it difficult to take advantage of all the opportunities provided by ICTs today for the distribution of their products.

Moreover, concerning accessibility, it is obvious that tourism development is closely linked to the development of means of transporting, since, by definition, tourism involves tourists travelling outside your normal place of residence. Regarding this issue, the expert panel seems to agree on the idea that Spain has good transport connections with major origin countries, which facilitates its market positioning as a destination in these markets. However, they criticise some issues such as, for instance, that low cost airlines located in many Spanish destinations, especially in the urban ones, generate a dangerous dependence which may jeopardize their future viability as destinations. Airport management is criticised as well, being the reasons, among others, the existence of underutilised airports or disproportionate public investments in covert promotion to encourage the arrival of low cost companies. Regarding transport and sustainability, the results show a high level of agreement on the lack of a solid commitment, neither public nor private, to consolidate a network of intermodal transport; which would favour a more sustainable passenger transport, and would make the resources allocated to it more profitable.

With regard to consumption of the productdestination, in the opinion of experts, value for money dominates the market. Customers know exactly what they want and have complete information available; hence, they are becoming increasingly demanding and aim to get more for less at all times. Showing a relative agreement, respondents argue that the Spanish tourism businesses and workers maintain a culture of service providers instead of creators of valuable experiences, special and unforgettable, which is what tourists are seeking nowadays. With the same level of agreement, they think that tourism workers 
have lost much of the commitment to service and friendliness that characterised this group for a long time. Finally, concerning the commitment to a responsible tourism consumption, Delphi results reveal, with a high level of agreement, that, on the one hand, Spanish tourism offer does not include tourism products that promote responsible consumption on the part of tourists, so they cannot feel and enjoy this type values by consuming tourism; and, on the other hand, that Spanish businesses and destinations do not encourage responsible tourism consumption.

Regarding the post-consumption stage, its management is a major challenge for businesses and destinations, since, as supported by Ortega and Rodriguez (2005), the actions of tourism organisations aimed at attracting consumers should not end when the sale of the trip to the tourism destination is made, so post consumption management should be seen as a strategic action within the tourism destinations marketing. Regarding the actions related to sustainability, responsible consumption and its communication, experts consider that Spanish tourism destinations require, in general, post-consumption strategies aimed at customers who defend the values of sustainability. Moreover, they suggest that the promotion of this kind of actions after experiences in sustainable destinations fosters the communication of sustainability and its benefits to potential travellers.

Finally, the two cross-cutting issues included (knowledge management and governance) affect all the links of the value chain already included for the analysis of the incorporation of sustainability into Spanish tourism policy. Experts agree that there are significant weaknesses in both aspects. Spain does not have a tourism knowledge system, that is appropriate to its global importance, as a tourism destination. Besides, the planning and tourism management processes developed so far in the country, with few exceptions, have done little to encourage stakeholders' participation, even leaving many of them out, which, on the other hand, has generated tensions that hardly help achieve sustainable tourism.

\section{Proposal for a strategic agenda for the incorporation of sustainability into Spanish tourism policy}

Once the assessment of the realities of Spanish tourism has been carried out, it is possible to formulate specific strategies aimed at facing those realities from the perspective of sustainability. This section is devoted to that task.

Since the volume of ideas and proposals made by the participants was very high, it was decided to reduce the information analysed in this section. In this sense, we must bear in mind that, in order to ensure the coherence and consistency of the contents proposed for the future strategic agenda, it was agreed, after consultation with the experts, that only the first five key ideas of each component (aims, objectives and strategies) would be used to shape the elements that make up the agenda. It should also be noted that, since many of the ideas or recommendations made during the discussion coincided, again with the blessing of the experts, it was decided to group some of them, with the purpose of including as many contributions of interest as possible in the content proposal. Table 4 contains the main ideas discussed by the group regarding what the aims of a Spanish tourism policy committed to sustainability should be. They are ranked from highest to lowest mean obtained; in case of identical mean, the ordering criterion was the lowest $V_{x}$. It is important to remember that experts not only provided force ideas, obtained after reading the results of the previous Delphi analysis, but they were also asked to assess them using a Likert scale from (7) extremely important to (1) extremely unimportant. The first five items (Table 4), which have generated a higher degree of agreement, are those proposed to shape the strategic agenda.

Next, the main proposals and ideas, discussed by the experts regarding the objectives that a tourism policy committed to sustainability in Spain should pursue, are included in Table 5. In this case, according to the focus group participants, it was decided to organise these objectives into three main groups: 
Incorporating sustainability into tourism policy: A strategic agenda for Spain

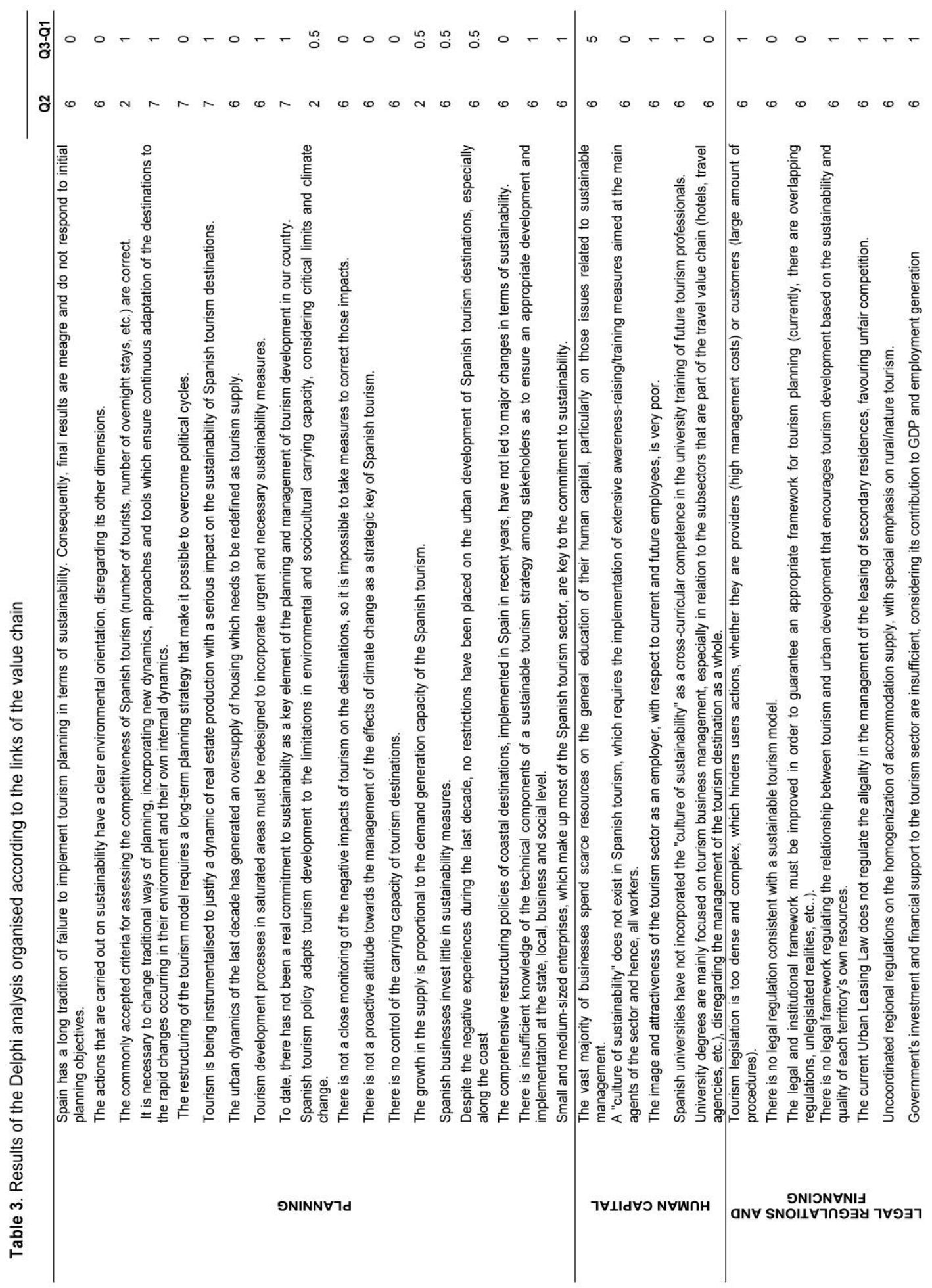




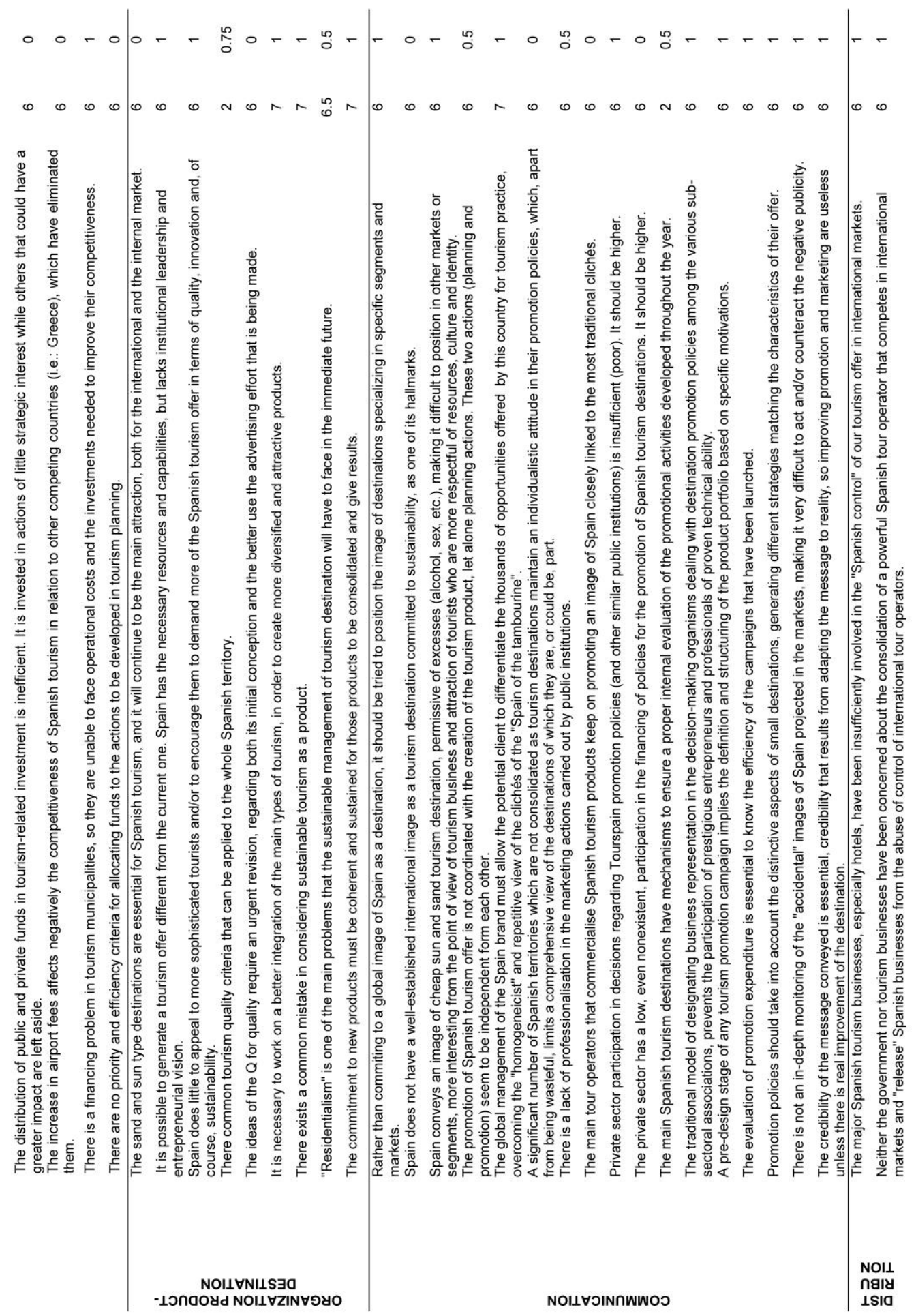


Incorporating sustainability into tourism policy: A strategic agenda for Spain

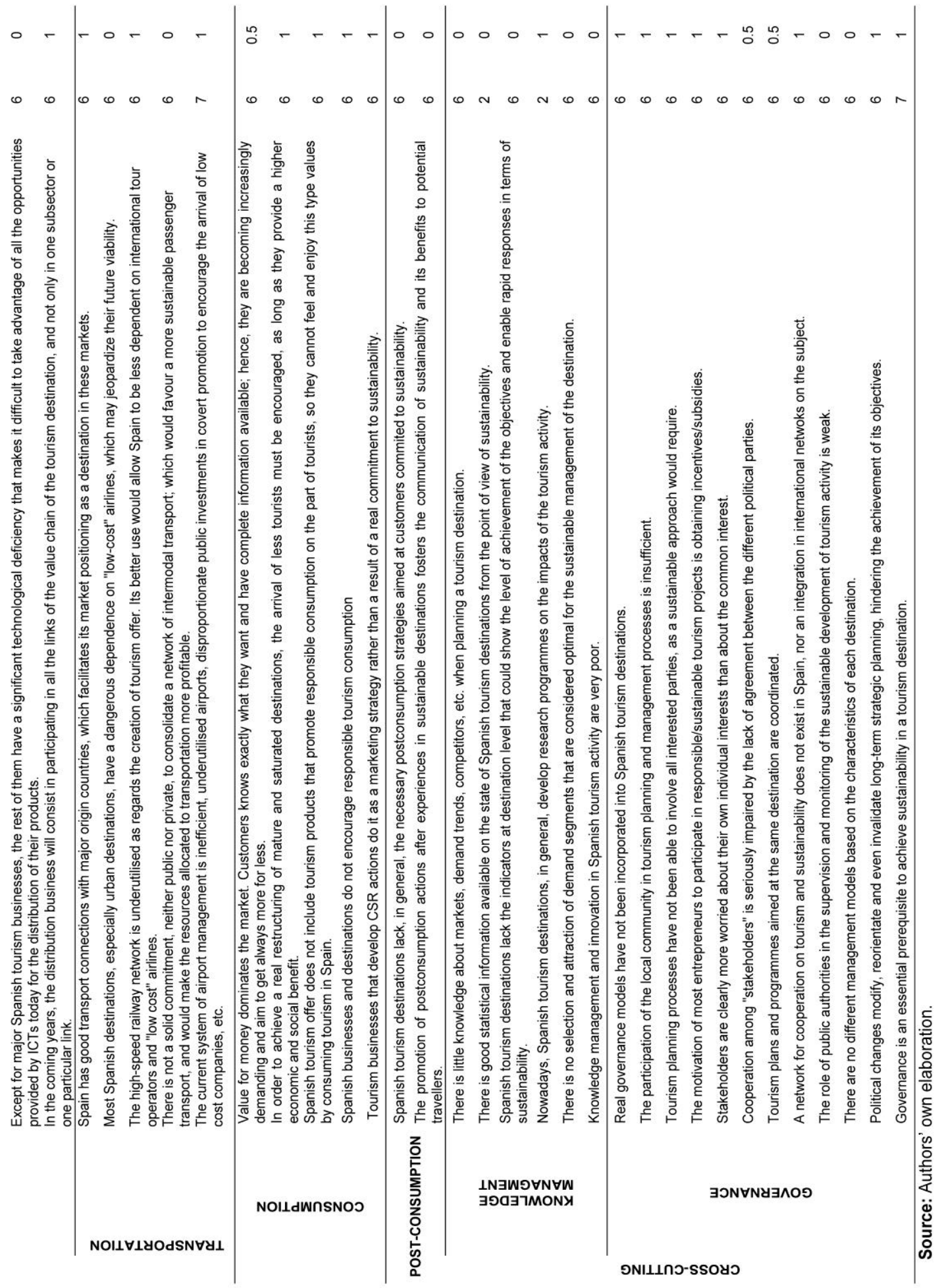


Table 4. Aims for a Spanish tourism policy with a view to sustainability

\begin{tabular}{lcc}
\hline \multicolumn{1}{c}{ Aims } & Mean & $\begin{array}{c}\text { Pearson's } \\
\text { coefficient of } \\
\text { variation (Vx) }\end{array}$ \\
\hline Institutionalise sustainability & 6.9 & 0.04 \\
Reinforce government leadership & 6.8 & 0.05 \\
Redefine the cornerstones of Spanish tourism competitiveness & 6.8 & 0.09 \\
Adopt a dynamic concept of sustainability & 6.6 & 0.07 \\
Contribute to a new tourism culture from a sustainable perspective & 6.5 & 0.06 \\
\hline
\end{tabular}

Source: Authors' own elaboration.

Table 5. Objectives for a Spanish tourism policy with a view to sustainability

\begin{tabular}{|c|c|c|}
\hline Process objectives & Mean & $\begin{array}{l}\text { Pearson's } \\
\text { coefficient } \\
\text { of variation }\end{array}$ \\
\hline $\begin{array}{l}\text { Replace the traditional tourism planning for a comprehensive planning, agreed and flexible } \\
\text { planning }\end{array}$ & 6.9 & 0.04 \\
\hline Identify alternatives to the current development model of Spanish tourism destinations & 6.9 & 0.04 \\
\hline $\begin{array}{l}\text { Accept that the objectives of tourism policy must be outlined in terms of making future } \\
\text { growth sustainable }\end{array}$ & 6.8 & 0.09 \\
\hline $\begin{array}{l}\text { Promote a legal and institutional environment that contributes to the transition to } \\
\text { sustainable tourism }\end{array}$ & 6.8 & 0.06 \\
\hline \multirow[t]{2}{*}{ Generate a new sustainable tourism culture } & 6.7 & 0.07 \\
\hline & Mean & $\begin{array}{l}\text { Pearson's } \\
\text { coefficient } \\
\text { of variation }\end{array}$ \\
\hline $\begin{array}{l}\text { Reinforce public authorities involvement in the supervision and monitoring of tourism } \\
\text { sustainability }\end{array}$ & 6.8 & 0.06 \\
\hline Encourage an adaptive management of Spanish tourism destinations & 6.8 & 0.09 \\
\hline $\begin{array}{l}\text { Generate and manage new knowledge that can be applied to the creation of more value } \\
\text { using fewer resources }\end{array}$ & 6.7 & 0.09 \\
\hline Activate human capital as a strategic element for the generation of value & 6.6 & 0.1 \\
\hline \multirow[t]{2}{*}{ Improve the management of all interrelations of Spanish tourism system } & 6.5 & 0.1 \\
\hline & Mean & $\begin{array}{l}\text { Pearson's } \\
\text { coefficient } \\
\text { of variation }\end{array}$ \\
\hline $\begin{array}{l}\text { Reorganise the tourism production process, promoting the integration of all actors } \\
\text { involved }\end{array}$ & 6.7 & 0.07 \\
\hline Encourage the incorporation of demand policies & 6.7 & 0.09 \\
\hline $\begin{array}{l}\text { Ensure a greater control over Spanish tourism product and the image of Spain by Spanish } \\
\text { companies and destinations }\end{array}$ & 6.6 & 0.07 \\
\hline $\begin{array}{l}\text { Move towards a new corporate image of Spain as a tourism destination that highlights the } \\
\text { values of sustainability }\end{array}$ & 6.6 & 0.1 \\
\hline Generate clear multichannel distribution and commercialisation strategies & 6.4 & 0.1 \\
\hline
\end{tabular}

\section{Source: Authors' own elaboration.}

1. Process objectives: refer to the methods, techniques, equipment and/or abilities used logically to provide a better tourism product and/or service. These methods and activities have a direct impact on the value proposition of the good or service in question. Normally, these objectives are aimed at improving efficiency or productivity. 
2. Management objectives: are related to stakeholders' decision making in order to improve performance in the tourism management of destinations. Therefore, they seek to achieve optimal results in the use of the resources available to satisfy the needs required (consumers, markets, residents, etc.). Actions aimed at creating spaces for the promotion and achievement of the interaction between the actors of the whole tourism system and the generation of consensus on approaches to sustainability.

3. Product objectives: are related to the requirement of addressing customers' needs more effectively, opening new markets and/or achieving a better position of the product or service in the market to increase sales.

Once identified, the aims and objectives, Table 6 summarises the main strategies discussed and accepted by those invited to participate in the focus group. However, in contrast with the previous two cases (aims and objectives), in which it was decided to include only five of the force ideas proposed by experts, in this occasion it was agreed to consider all strategies discussed by the participants in the focus group, in order to, first, show the fruitfulness of the process, and, second, provide as many ideas and solutions as possible to be incorporated in the future strategic agenda. It should be noted that the original work includes a set of standard actions, proposed by the respondents themselves, in order to guide the content of each strategy, which are omitted in this paper for reasons of space. Thus, the different strategies (process, management and product) that should make up the strategic agenda for the incorporation of sustainability into Spanish tourism policy are shown. Moreover, this table presents the crosscutting strategies, those which affect the incorporation of sustainability into tourism in any of the links of the value chain, and therefore, cannot be classified exclusively in any of the three groups previously considered.

\section{Conclusion}

The purpose of developing a strategic agenda for incorporating sustainability into Spanish tourism policy was twofold: on the one hand, to provide policymakers and destination managers with the keys to reformulating the tourism policy of Spanish destinations, incorporating a basic element for their competitiveness; and, on the other hand, to advance research in this field through an analytical and interrelated opinion process in which different stakeholders would be actively involved.

This paper presents the results of the study that has been carried out, which are specified in a conceptual framework that can be adapted for its flexible implementation in any tourism destination, and highlight, in a structured way, the priorities that policymakers and managers of Spanish tourism destinations must face in the area under study.

This article provides practical and very useful guidelines to study the incorporation of sustainability into tourism public policies. The proposed strategic agenda is in no way exhaustive, though, as far as it is representative of the reality of one of the world's top tourism destinations, it represents an important contribution to the body of literature on the issues analysed and enables apart from the understanding of the Spanish realities and the contribution to the debate on the need for a change in the tourism model of this country- the identification of a set of issues of great interest not only for the destination analysed, but for many others, and even to guide future research and deal with the problems and challenges that the management of sustainability faces in the field of tourism policy.

The results obtained allow for the organisation of the conclusions of this paper around three major contributions: theoretical developments, empirical contributions and practical implications. Firstly, regarding theoretical developments, this study has proven that the value chain of the tourism destination is a very useful tool for both the assessment and the subsequent planning and management of tourism policy. Its use allows for a holistic view of the tourism phenomenon and of each of the links through which tourism agents generate value to the tourists. In recent years, the main trend analyses are making constant reference to the need to "think" the value chain of the destination as a whole, and not in isolation, by 


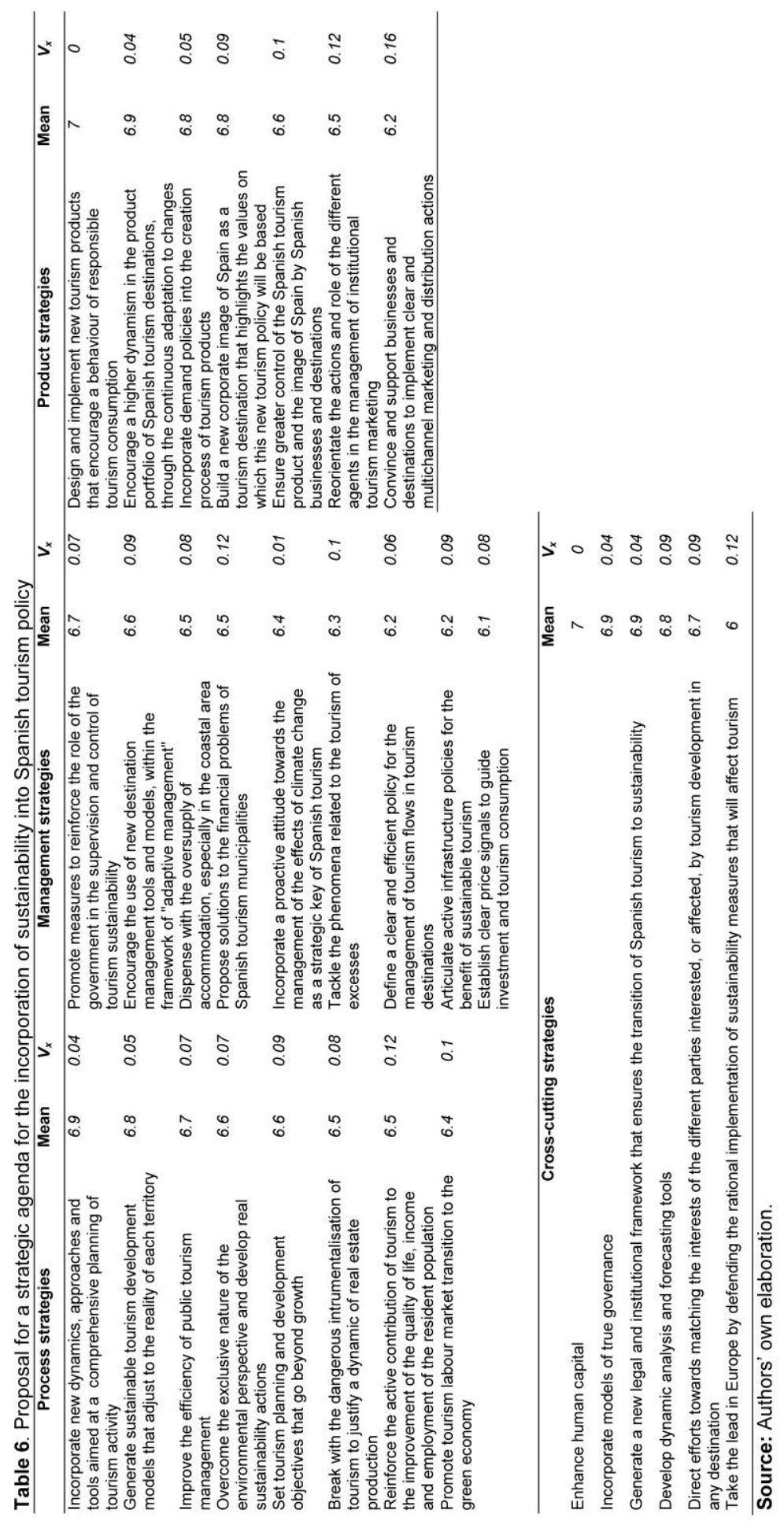


sub sectors, as has been traditionally done, hence the importance of having introduced this concept for the analysis of the situation of tourism in Spain in terms of sustainability. Sustainability must be a central factor in the competitiveness of tourism destinations, but tourism will be sustainable only when public guidelines are aimed at a general economic progress, and when it respects the limits to the exploitation of their resources and is able to equitably meet the needs of the society in which it operates. Secondly, among the main empirical contributions of this paper, it is worth noting the unquestionable fact the success or failure of the transition towards a more responsible and sustainable tourism depends, ultimately, on policy makers, who must understand how, and with what policies, the transition towards a more competitive tourism that is more efficient in the use of resources can be promoted and accelerated. Therefore, political inaction or wrong decisions have a direct impact on the loss of competitiveness of tourism destinations, even allocating public funds to projects that have a negative impact on the territory, which shows the importance of having an appropriate institutional framework as a sine qua non for achieving sustainability.

In the specific case of Spain, which can be extended to other countries and tourism destinations, experts have raised the need to institutionalise sustainability, that is, to ensure that it is at the core of the tourism policy of any destination and of the actions of any business or agent that operates there. In addition, efforts have to be made to achieve the integration of sustainability into the sectored policies of the different departments related to tourism. It is therefore essential that the public administrations take the lead in the promotion of sustainability as an added value of Spanish tourism, beyond its rhetorical, or even politically correct, but meaningless use. As recognised by scientific literature, the threefold dimension of sustainability will not be achieved unless a sound institutional framework is created that legitimises and demands firm commitments regarding this issue. Moreover, in this process of change, public administrations in any destination are not alone, as there is an increasing volume of contributions at supranational level (in recent years, more of an applied than a theoretical nature, as major policymakers and public managers have been requesting) that are intended to help those administrations with competences in the field of tourism planning and management to have tools available that facilitate the assumption of this leadership that they are being asked for. Furthermore, the private sector is also taking significant steps in this direction, being aware that there are no successful companies in unsuccessful territories and that, even owing to a matter of purely commercial interest, it is necessary to preserve the resource base on which their business depends.

Finally, regarding the practical implications of this work, it should be noted that, although it is the Government (at its different levels) which is able to develop public policies to incorporate sustainability into tourism management, it requires the collaboration of all stakeholders to ensure their successful implementation and development.

Apart from that, the experts consulted during this research suggest that, in general, stakeholders are trying to seek the maximum individual benefit, which may lead to situations that are socially inefficient. Experts note that most entrepreneurs involved in responsible/sustainable tourism projects are motivated by incentives and/or subsidies; and besides, that political vicissitudes, as a consequence of the changes of government due to periodic elections, modify, reorient, and even cancel long-term strategic planning, hindering the achievement of its objectives.

Hence the need for an institutional involvement that ensures the incorporation of new management methods through different organisations, both professionalised and independent of the individual interests of each stakeholder, which assume responsibility for the destination and its products as a whole, as well as promote and participate in the most diverse forms of collaboration, managing public and private resources in order to develop a proactive tourism policy aimed at continuously improving the competitive performance of the destination. 


\section{References}

Aaker, D., V Kumar, G. Day, (2003). Marketing research. New York: John Wiley \& Sons, Inc.

Briedenhann, J., S. Butts. (2006). Application of the Delphi technique to rural tourism project evaluation. Current Issues in Tourism 9 (2), 171-190.

Buhalis, D. (2000). Marketing the competitive destination of the future. Tourism Management 21 (1), 97-116.

Casanueva, L. (2010). Reinventar la Marca España. Revista de Economía y Gestión de Viajes 79, 64-65.

Cebrián, A. (2008). Turismo rural sostenible. In F. Cebrián (Coord.) (2008) Turismo Rural y Desarrollo Local. SevillaCuenca: University of Sevilla-University of Castilla La Mancha, 49-56.

Chambers, R. (1986). Sustainable livelihoods: An ppportunity for the World Commission on Environment and Development. Mimeo. Brighton: Institute of Development Studies, University of Sussex.

Chambers, R. (1987). Sustainable livelihoods, environment and development: putting poor rural people first. IDS Discussion Paper 240. Brighton: Institute of Development Studies, University of Sussex.

Choy, D. J. L. (1991). Tourism planning: The case for market failure. Tourism Management 12(4), 313-330.

Dalkey, N. C., B. Brown, S. W. Cochran, F. Rostand (1972). La prevision a long terme par la méthode DELPHI. Paris: Ed. Dunod,

Dodds, R., R. W. Butler (2009). Inaction more than action: barriers to the implementation of sustainable tourism policies. In S. Gössling, M. Hall, \& D. B. Weaver (Eds.) (2009). Sustainable tourism futures. London: Routledge, 43-57.

Dodds, R. (2012). Sustainable tourism: A hope or a necessity? The case of Tofino. Journal of Sustainable Development 5(5), 54-64.

Donohoe, H. M. (2011a). Defining culturally sensitive ecotourism: a Delphi consensus. Current Issues in tourism 14(1), 27-45.
Donohoe, H. M. (2011b). A Delphi toolkit for ecotourism research. Journal of Ecotourism 10(1), 1-20.

Donohoe, H. M., R. D. Needham (2009). Moving best practice forward: Delphi. Characteristics, advantages, potential problems and solutions. International Journal of Tourism Research 11 (5), 415-437.

Enríquez, M. A., M. Osorio, M. Castillo, A. Arellano (2012). Hacia una caracterización de la política turística. PASOS. Revista de turismo y patrimonio cultural 10(3), 417-428.

Evans, N., D. Campbell, G. Stonehouse (2003). Strategic management for travel and tourism. Oxford: ButterworthHeinemann.

Fabricius, M. P. (2001). Competitive strategies for tourism destinations. Pretoria: Unpublished MBL Research Report. University of South Africa.

Folch, R. (2008) El paradigma sostenibilista. Futuros, 6(20). URL: http://www.revistafuturos.info/futuros20/ par_sostenabilidad.htm (Accesses on: 16. 10.2012).

Folch, R. (2009). Socio-ecology and Sustainability. Transfer: Journal of Contemporary Culture 4, 62-77.

Goldin, I. (2010). Tourism and the G-20: T.20 Strategic Paper. Document prepared for the 2nd T.20 Ministers Meeting Republic of Korea, 11-13 October 2010, University of Oxford.

Gomm, R. (2004). Social research methodology: A critical introduction. New York: Palgrave Macmillan,

Green, H., C. Hunter, B. Moore (1990). Assessing the environmental impact of tourism development: use of the Delphi technique. Tourism Management 11(2), 111-120.

Hall, C. M., J. Jenkins (1995). Tourism and public policy. New York: Routledge.

Hall, C. M. (2000). Tourism Planning: Policies, Processes and Relationships. Singapore: Pearson Education Ltd.

Hamel, J. L. (2005a). Knowledge for sustainable development in Africa: towards new policy initiatives. Word Review of Science, Technology and 
Sustainable Development 2 (3/4), 216243.

Hamel, J. L. (2005b). Unleashing the Power of Knowledge for Sustainable Development in Africa: Fundamental Issues for Governance and Meeting MDGs, Economic Commission for Africa, Addis Ababa. URL: http://www.uneca.org/estnet/Ecadocum ents/Knowledge_for_Sustainable_Deve lopment.doc (Accessed on: 30.9.2012).

Harris, R., T. Griffin, P. Williams (2002). Sustainable tourism: a global perspective. Burlington: Elsevier.

Hassan, S. S. (2000). Determinants of market competitiveness in an environmentally sustainable tourism industry. Journal of Travel Research 38(3), 239-245.

Hidalgo-Capitan, A. L. (2012). "Sostenibilismo". Ideologizando la sostenibilidad. Estudios de economía política 21, 5-23.

Jenkins, C. L. (1980). Tourism Policies in Developing Countries: A Critique. International Journal of Tourism Management 1, 22-29.

Jiménez, L. M. (2007). Hacia la sostenibilidad turística en España. Estudios Turísticos 172-173, 73-79.

Johnson, P., B. Thomas (1992). Perspectives on Tourism Policy. London: Biddles Ltd.

Kaynak, E., J. Macaulay (1984). The Delphi technique in the measurement of tourism market potential: the case of Nova Scotia. Tourism Management 5 (2), 87-101.

Krueger, R. (1998). Designing and Conducting Focus Group Interviews: Seminar Notes. Sydney: University of Western Sydney.

Lane, B. (2012). Sustainable rural tourism strategies: A tool for development and conservation. Revista Interamericana de Ambiente y Turismo 1 (1), 12-18.

Linstone, H., M. Turoff (1975). The Delphi Method: Techniques and Applications. Reading, MA: Addison-Wesley.

Liu, J. (1988). Hawaii tourism to the year 2000: A Delphi forecast. Tourism Management 9 (4), 279-290.

Liu, Z. (2003). Sustainable tourism development: a critique. Journal of Sustainable Tourism, 11 (6), 459-475.
Lloyd, J., J. M. La Lopa, C. G. Braunlich (2000). Predicting changes in Hong Kong's hotel industry given the change in sovereignty from Britain to China in 1997. Journal of Travel Research 38 (4), 405-410.

Merton, R., M. Fiske, P. Kendall (1990). The Focused Interview. New York: Free Press.

Miller, G. (2001). The development of indicators for sustainable tourism: results of a Delphi survey of tourism researchers. Tourism Management 22 (4), 351-362.

Mitchel, J., L. C. Phuc (2007). Final Report on Participatory Tourism Value Chain Analysis in Da Nang, Central Vietnam. Vietnam: Vietnam Private Sector Support Programme.

Munasingue, M. (1993). Environmental Economics and Sustainable Development. Washington DC: Environmental Paper 3, World Bank.

Ortega, E., B. Rodríguez (2005). Importancia de la comunicación en los destinos turísticos internacionales: Percepción de los turistas extranjeros en los destinos españoles. Cuadernos de Turismo 15, 169-188.

Pan, S. Q., M. Vega, A. J. B. H. VellaArcher, G. Parlett (1995). A Mini-Delphi Approach: An Improvement on Single Round Techniques. Progress in Tourism and Hospitality Research 2 (1), 27-39.

Park, D. B., Y. S. Yoon (2011). Developing sustainable rural tourism evaluation indicators. International Journal of Tourism Research 13 (5), 401-415.

Pedreño, A., A. B. Ramón (2009). El turismo: globalización, competitividad y sostenibilidad. Mediterráneo Económico 16, 227-256.

Perelli, O. (2011). Por una nueva cultura de litoral basada en su revalorización turística como motor de la recuperación. Papeles de economía española 128, 3-71.

Pigram, J. J. (1990). Sustainable tourism policy considerations. Journal of Tourism Studies 1 (2), 2-9.

Poon, A. (1993). Tourism, technology, and competitive strategies. Wallingford: $\mathrm{CAB}$ International. 
Porter, M. (1985). Competitive Advantage. New York: Free press.

Pulido J. I., Y. López, (2011). Tourism. Analysis of a Global Phenomenon from a Perspective of Sustainability. In $P$. Pachura (Ed.) (2011) The systemic dimension of globalization. Croatia: InTech. Open Access Publisher, 257278.

Pulido, J. I. (2004). El medio ambiente en la política turística española. Quaderns de política económica 7, 93-114.

Pulido, J. I. (2011). La sostenibilidad del modelo turístico español en un escenario de cambio global. Papeles de Economía Española 128, 38-52.

Riera, A. (dir.) et al. (2009). Libro Blanco del turismo de las Islas Baleares. Hacia una nueva cultura turística. Mallorca: Conselleria de Turismo-Govern de les Illes Balears, Universitat de les Illes Balears, "SA NOSTRA" Caixa de Balears, Cambra de Comerç de Mallorca.

Ritchie, J. B., G. I. Crouch (2003). The competitive destination: A sustainable tourism perspective. UK: Cabi.

Seely, R. L., H. Iglarsh, D. Edgell (1980). Utilizing the Delphi technique at international conferences: A method for forecasting international tourism conditions. Travel Research Journal 1 (1), 30-35.

Sharpley, R. (2009). Tourism Development and the Environment: Beyond Sustainability? London: Earthscan.

Spenceley, A. (2005). Nature-based Tourism and Environmental Sustainability in South Africa. Journal of Sustainable Tourism 13(2), 136-169.

Taylor, G. D. (1976). The Delphi Technique as a tool for travel research. Travel Research Association-Canada Chapter Vancouver Seminar Proceedings, 15, 1.

Thomas, K. (2004). The Research Process as a Journey: From Positivist Traditions into the Realms of Qualitative Inquiry. In J. Phillimore, L. Goodson, (Eds.), Qualitative Research in Tourism: Ontologies, Epistemologies and Methodologies. London: Routledge, 333-346.
UNEP, ICLEI (2003). Tourism and Local Agenda 21: The Role of Local Authorities in Sustainable Tourism. Paris: UNEP.

Van Ginneken, R. (2011). Expert Attitudes to Management Contracts in the Dutch Hotel Industry: a DELPHI approach. Journal of Hospitality and Tourism Management 18 (1), 140-146.

Velasco, M. (2010). La incorporación de ideas en las políticas públicas. El concepto de sostenibilidad en la política turística. Revista de Análisis Turístico 10, 35-44.

Vera, J. F., C. J. Baños (2010). Renovación y reestructuración de los destinos turísticos consolidados del litoral: las prácticas recreativas en la evolución del espacio turístico. Boletín de la Asociación de Geógrafos Españoles 53, 329-353.

Voinov, A. (2008.) Understanding and communicating sustainability: global versus regional perspective. Environment, Development and Sustainability 10, 487-501.

Waligo, V. M., J. Clarke, R. Hawkins (2012) Implementing sustainable tourism: A multi-stakeholder involvement management framework. Tourism Management 36, 342-353.

Weber, K., \& Ladkin, A. (2003). The Convention Industry in Australia and the United Kingdom: Key Issues and Competitive Forces. Journal of Travel Research, 42, 125-132.

Wheeler, B. (1993). Sustaining the ego. Journal of Sustainable Tourism 1, 121-129.

Wheeller, B., T. Hart, P. Whysall (1990). Application of the Delphi technique: A reply to Green, Hunter and Moore. Tourism Management 11 (2), 121-122.

World Travel Organization (WTO) (1998). Guide for Local Authorities on Developing Sustainable Tourism. Madrid: World Tourism Organization.

Yasarata, M., Altinay, L., Burns, P., \& Okumus, F. (2010). Politics and sustainable tourism development - can they coexist? Voices from North Cyprus. Journal Tourism Management, 31(3), 345-356.

Yilmaz, Y. \& Bititci, U.S. (2006). Performance measurement in tourism: a value chain 
model. International Journal of Contemporany

Management, 18(4), 341-349.

Yong, Y. W., Keng K. A., \& Leng, T. L. (1989). A Delphi Forecast for the Singapore Tourism Industry: Future Scenario and Marketing Implications. International Marketing Reviews, 6(3), 35-46.

Younis, T. (1990). Implementation in Public Policy. London: Billing \& Sons Ltd.

Yüksel A., Yüksel, F., \& Culha, O. (2012). Ministers' statements: a policy implementation instrument for sustainable tourism? Journal of Sustainable Tourism, 20(4), 513-532.

Yunpeng, L., Yongqiu, X., Min, N., Yu, H., \& Lina, Q. (2011). Research on Dynamic
Optimized Approach of Value Chain in Tourist Destinations. In R. Lee, (Ed.). Computer and Information Science (pp. 191-199). Berlin: Springer-Verlag.

Zhang, J., Zhang, J., \& Liu, J. (2005). Research on Combination Pattern of tourism industry based on the value chain theory and relevant technology. Science of Tourism (1).

Zhao, L., Cao, G., \& Liu, M. (2009). The Reconfiguration of Tourism Value Chain Based on E-Commerce. In Proceedings of 2009 International Conference on Management of eCommerce and e-Government (522525). IEE Computer Society. 